In María del Pilar García-Mayo \& Roger Hawkins (eds, 2009) Second language acquisition of articles: Empirical findings and theoretical implications. Amsterdam: John Benjamins, pp. 201-232.

\title{
ARTICLES IN TURKISH/ENGLISH INTERLANGUAGE REVISITED: IMPLICATIONS OF VOWEL HARMONY*
}

\author{
Heather Goad and Lydia White \\ McGill University
}

\section{Introduction}

A well-studied area in second language (L2) research relates to the difficulties that L2 learners' have with the acquisition of articles. Although the problems have been examined from a number of different perspectives, a common assumption is that absence of articles in the L1 causes difficulties when the L2 requires articles. For example, learners must determine how the L2 article system encodes features such as definiteness or specificity (e.g. Tsimpli 2003; Ionin, Ko \& Wexler 2004; Leung 2005) and how the article system works with respect to the count/mass distinction (e.g. Snape 2008). In most research, emphasis has been placed on morphosyntactic, semantic or discourse related properties of articles. While agreeing on the importance of the L1 in shaping interlanguage representation, we have argued that the determinants of success or lack of success in L2 article production include L1 prosodic representations. This position is known as the Prosodic Transfer Hypothesis (PTH) (Goad, White \& Steele 2003; Goad \& White 2004, 2006).

According to the PTH, L2 learners have difficulties constructing prosodic representations for inflectional morphology and function words which are disallowed in the L1 but required to produce the L2 in native-like fashion. Consequently, L2 learners rely on the L1 in building interlanguage prosodic representations. They may resort to a variety of strategies in production, including article deletion and stressing of articles, as well as exhibiting asymmetries in suppliance of target-like articles depending on prosodic conditions.

In previous work (Goad \& White 2004, 2009), we have tested the predictions of the PTH with respect to the production of English articles by Turkish speakers, Turkish being a language without a definite article. We assume (following Selkirk 1996) that English articles link directly to the Phonological Phrase (PPh) and we have argued that Turkish lacks this possibility. Although some more advanced Turkish-speaking learners of English acquire the target representation (Goad \& White 2009), we have proposed that less advanced speakers principally adopt two representations from the L1: (i) the independent prosodic word (PWd) representation required for other determiners in Turkish, which results in articles being stressed under conditions where this would not be appropriate for English; and (ii) the PWd adjunction structure required for the Turkish indefinite article. As a consequence of resorting to (ii), learners show asymmetries in article production depending on whether or not an adjective is present (see sections 3 and 4 ).

In the present paper, we argue that a subset of the subjects we have previously reported on employ yet another prosodic representation for articles in English, namely a PWd-internal representation. We base this claim on the observation that these subjects often show vowel harmony in English DPs with unstressed articles. We discuss the implications of this finding for

* We would like to thank Will Dalton, Luisa Meroni and Jen Morehouse for research assistance, and Alyona Belikova, Eva Dobler, Eva Melkonyan, Maíre Noonan, Öner Özçelik, Sasha Simonenko,Tobin Skinner, Lisa Travis and two anonymous reviewers for helpful comments and discussion. Special thanks to Ayșe Gürel for organizing the testing in Turkey. This research was funded by grants from SSHRCC and FQRSC. 
the interlanguage representation of English articles, in particular, and for the PTH more generally.

\section{Articles in English and Turkish}

As already mentioned, our focus is on the acquisition of English articles by L1 speakers of Turkish. The article systems of these languages differ as follows. English has two articles, dependent on the feature [ \pm definite], the being definite and $a$ indefinite. Singular count nouns must take an article, whereas mass nouns and plural nouns take the definite article but can be bare if they are indefinite, as shown in (1).

a. a book, the book, *book

b. *a furniture, the furniture, furniture

c. *a books, the books, books

In Turkish, there is only an indefinite article, unstressed bir, as shown in (2a). ${ }^{1}$ Articles can be omitted in certain contexts, as seen in $(2 b)$. The interpretation of a bare noun as definite or indefinite depends on a number of factors, including word order and case marking. Bare nouns typically receive a definite interpretation in subject position and are potentially ambiguous elsewhere. When bir is stressed, as in (2c), it is interpreted as the numeral one (Erguvanli 1984; Kornfilt 1997; Öztürk 2005; amongst others).
a. bir kitáp
'a book'
b. kitáp
c. bír kitap
'a book, the book'
'one book'

We have argued previously that the two English articles share the same prosodic representation and that this differs from the representation appropriate for Turkish bir (Goad \& White 2004, 2009). Motivation for this difference is discussed in the next section after the relevant aspects of Turkish vowel harmony are introduced.

\section{Vowel harmony and the determination of prosodic representation in Turkish/English interlanguage}

In order to test the predictions of the PTH for article production, it is necessary to establish what prosodic representations are available in the L1 and how these differ from what is required in the L2. Turkish, unlike English, is a language with vowel harmony. We argue below that the domain of harmony in Turkish is the lower PWd and, following from this, that the presence of vowel harmony in the interlanguage grammar provides a means of determining certain aspects of prosodic structure.

\subsection{Vowel harmony in Turkish}

We begin by briefly detailing the harmony system. Turkish is a symmetrical eight-vowel system, as can be seen in (3). ${ }^{2}$

1 There is some dispute about the status of unstressed bir. Kornfilt (1997) considers it to be an article, while Underhill (1976) treats it is a numeral. Lyons (1999) refers to it as a 'quasi indefinite article', but argues that definiteness is not grammaticalized in Turkish (see also Öztürk 2005).

2 Although [i] is the symbol typically used to represent the high back unrounded vowel in the literature on Turkish, we have chosen to use [u] instead, as the central-back distinction becomes relevant in the manifestation of harmony in the L2 (see section 5). 
(3)

\begin{tabular}{|l|c|c|c|c|}
\cline { 2 - 5 } \multicolumn{1}{c|}{} & \multicolumn{2}{c|}{ Front } & \multicolumn{2}{c|}{ Back } \\
\cline { 2 - 5 } \multicolumn{1}{c|}{} & Unrnd & Round & Unrnd & Round \\
\hline High & $\mathrm{i}$ & $\ddot{\mathrm{u}}$ & $\mathrm{u}$ & $\mathrm{u}$ \\
\hline Non-high & $\mathrm{e}$ & $\ddot{\mathrm{o}}$ & $\mathrm{a}$ & $\mathrm{o}$ \\
\hline
\end{tabular}

Vowel harmony ensures that suffixes with high vowels agree in backness and rounding with the preceding vowel (see (4a)); suffixes with non-high vowels agree only in backness (see (4b)) (examples from Clements \& Sezer 1982). The preceding vowel can be either the last vowel in the root (e.g. [elma-lar] 'apple-PL') or the vowel of the immediately preceding suffix (e.g. [köy-lêr-in] 'village-PL-GEN').

$\begin{array}{lll}\text { a. Genitive: } & \text { b. } & \begin{array}{l}\text { Plural: } \\ \text { ip-ler }\end{array} \\ \text { ip-in } & \text { el-ler } & \text { 'rope' } \\ \text { el-in } & \text { yüz-ler } & \text { 'fand' } \\ \text { yüz-ün } & \text { köy-ler } & \text { 'village' } \\ \text { köy-ün } & \text { kuz-lar } & \text { 'girl' } \\ \text { kuz-un } & \text { sap-lar } & \text { 'stalk' } \\ \text { sap-un } & \text { pul-lar } & \text { 'stamp' } \\ \text { pul-un } & \text { son-lar } & \text { 'end' } \\ \text { son-un } & \end{array}$

\subsection{The role of the PWd in Turkish vowel harmony}

As our concern in this paper is with prosodic structure, we must establish the domain in which vowel harmony operates. Across languages, the usual domain for harmony is the lower PWd (cf. van der Hulst \& van de Weijer 1995). At first glance, Turkish appears to be consistent with this. First, the inflectional affixes that undergo harmony also fall within the domain of stress assignment (with some exceptions; see below). The examples in (5a-b) reveal that, in the default case, word-level stress falls on the final syllable, regardless of lexical category (e.g. Sezer 1981, Kabak \& Vogel 2001, Inkelas \& Orgun 2003) (examples from Inkelas \& Orgun 2003).
a. arabá
araba-lár
'car'
araba-lar-dán
'car-PL'
'car-PL-ABL'
b. burak
burak-acák
burak-acak-lár
'leave!'
'leave-FUT'
'leave-FUT-3PL'

As the constituent in which stress is realized is the foot and the foot is, by definition, internal to the PWd, these harmonizing affixes must fall within the PWd; see (6).

(6)

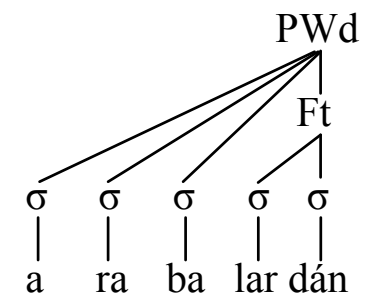

'car-PL-ABL' 
The second reason why it appears that the lower PWd defines the domain for vowel harmony is because each constituent in a compound forms a separate harmonic domain. See the examples in (7) (from Inkelas \& Orgun 1998).

$$
\begin{array}{ll}
\begin{array}{l}
\text { orhan }+ \text { bey } \\
\text { name }+ \text { mister }
\end{array} & \text { 'Mr Orhan' } \\
\begin{array}{l}
\text { ye-mek + oda-su } \\
\text { eat-INF + room-POSS }
\end{array} & \text { 'dining room' }
\end{array}
$$

This is as expected because each constituent in a compound constitutes a separate PWd, as can be seen in (8).

(8)

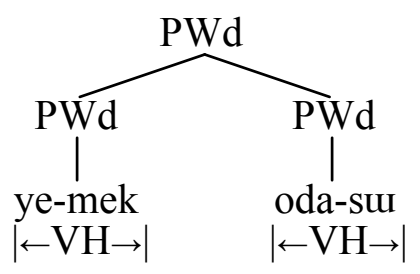

However, the assumption that the domain of vowel harmony is the lower PWd appears to be challenged by the behaviour of so-called 'pre-stressing' suffixes. Pre-stressing suffixes cause stress to fall on the syllable immediately to their left. The examples in (9a) demonstrate the regular stress pattern while those in (9b) show the effects of pre-stressing suffixes (underlined) (examples from Özçelik 2008).
a. dinle-dí
listen-PAST
gel-mé 'coming'
come-NOM
'He listened'
b. dinle-dí-de
'He listened, too'
listen-PAST-CONN
gél-me
come-NEG
'Don't come'

To capture their pre-stressing behaviour, Kabak \& Vogel (2001) and Newell (2005) argue that these suffixes are adjoined to the PWd, as in (10). ${ }^{3}$

3 This is somewhat of a simplification. Kabak \& Vogel argue that suffixes that display exceptional stress are organized into the Clitic Group. For present purposes, this can be equated with the recursive PWd structure provided in (10) for dinle-di-de. 


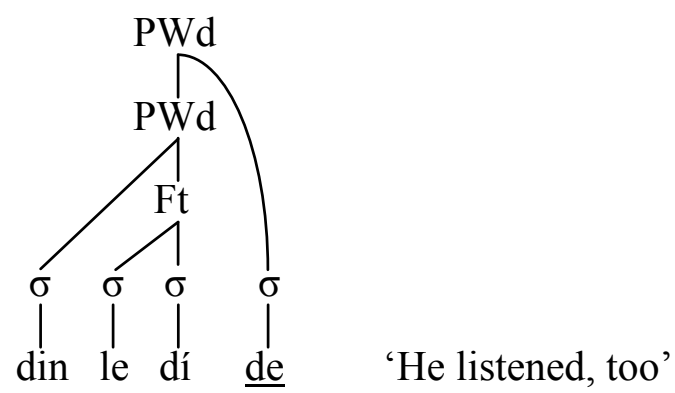

Under this analysis, these affixes fall outside the lower PWd, the putative domain of vowel harmony, yet they undergo harmony. Accordingly, Kabak \& Vogel argue that harmony in Turkish cannot be delimited by any prosodic domain; harmonic features instead spread rightward until they encounter another underlyingly-specified harmonic feature.

Since it will be critical for our analysis that the domain for vowel harmony indeed be the lower PWd, it is in our interest to point out the empirical shortcomings of the adjunction analysis of pre-stressing affixes in (10). Here, we follow Özçelik (2008). Özçelik observes that, under two conditions, pre-stressing suffixes themselves receive stress. The first is when these suffixes are followed by a single consonant suffix; see (11a). The second is when two pre-stressing suffixes are immediately adjacent; see (11b) where stress falls on the first such suffix rather than on the syllable to its left.
a. gel-mé-m, *gél-me-m come-NEG-1SG
b. gel-mé-de, *gél-me-de come-NEG-CONN
'I don't/wouldn't come'
'If you don't come, then...'

As Özçelik (2008) points out, if pre-stressing suffixes are adjoined to the PWd, they should never be bearers of stress, contrary to fact. He argues instead that these suffixes occur internal to the lower PWd. Their exceptional behaviour can then be captured through constraints which ensure that they are always contained somewhere inside a trochaic foot (similar to Inkelas \& Orgun 1998). The specific details of the analysis do not concern us here, but the resulting structure for dinle-di-de is shown in (12); compare this with (10).

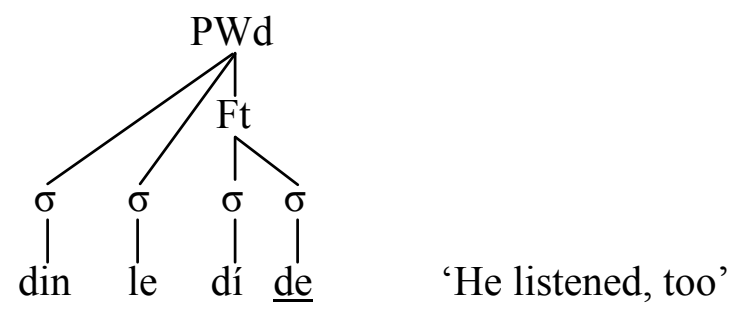

As is evident, one important consequence of Özçelik's (2008) analysis is that the domain of vowel harmony is indeed the lower PWd. We will return to the significance of this for our study in section 5 .

\subsection{Directionality}

The examples discussed thus far reveal that vowel harmony operates from left-to-right in Turkish. This is because Turkish has no bound morphology at the left edge (aside from unstressed bir; see below). As Turkish is a root-controlled system, harmony must originate in roots and spread to the bound morphology on their right. There is one context, however, where harmony can operate from right-to-left, namely in loanwords containing initial clusters 
(Clements \& Sezer 1982). In normal or colloquial speech, words of this shape undergo epenthesis to break apart the cluster. The examples in (13) show that, in labial- and coronalinitial clusters, the epenthetic vowel undergoes both backness and rounding harmony (examples from Clements \& Sezer 1982). ${ }^{4}$

Careful form:
[trišin]
[fren]
[transit]
[prusya]
[protesto]

Colloquial form:
[tirišin]
[firen]
[turansit]
[purusya]
[purotesto]

'trichinosis'
'brake'
'transit'
'Prussia'
'protest'

Thus far, we have seen that vowel harmony can operate bi-directionally in Turkish, targeting bound morphology to the right and epenthetic vowels to the left. Since we have argued in earlier work that the indefinite article, unstressed bir, is also bound (see below), we might expect it to undergo harmony. The data in (14) reveal that this is not the case.

$$
\begin{array}{ll}
\text { [bir sap], *[bur sap] } & \text { 'a stalk' } \\
\text { [bir pul], *[bur pul] } & \text { 'a stamp' }
\end{array}
$$

The absence of harmony in (14), however, is entirely as expected, if indefinite bir is adjoined to the PWd of its host, rather than being organized internal to this domain like the affixes in sections 3.1-3.2 and the epenthetic vowels in (13). Compare (15a,b) with (15c) where this is graphically illustrated. 5
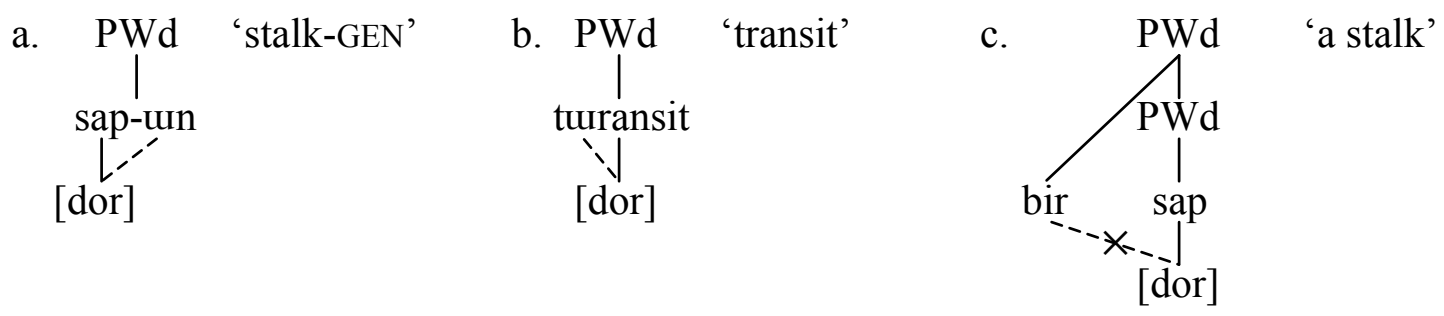

In the following section, we provide additional evidence that the representation in (15c) is correct for indefinite bir.

\subsection{The prosodic representation of indefinite bir and other determiners}

As we have just seen, the absence of vowel harmony in indefinite bir constructions suggests that bir cannot be organized into the lower PWd of its host. Further support for this analysis comes from syllabification. In PWd-internal constructions, syllabification crosses morpheme boundaries, such that root-final [r] in a word like [kir-in] 'dirt-GEN' becomes the onset of the syllable containing the suffix; see (16a) (examples in (16) from Öner Ozçelik, p.c.). However, in segmentally-parallel constructions that start with indefinite bir, intervocalic [r] retains its coda status, surfacing as ambisyllabic, as can be seen in (16b) for [bir ip] 'a rope'. Onset syllabification alone for $[\mathrm{r}]$ is not possible, we contend, because $[\mathrm{r}$ ] crosses over a lower PWd boundary.

\footnotetext{
4 Backness harmony is not observed with velar-initial clusters (e.g. [kuredi], *[kiredi] 'credit') and is only optionally observed with /s/-initial clusters (e.g. [sumokin], [simokin] 'dinner jacket'). In addition, rounding harmony does not always apply before /o/ (e.g. [buroš] 'brooch' vs. [purotesto] in (13)). We leave these cases aside.

5 We adopt the view that backness harmony in Turkish involves spreading (or sharing in non-derivational terms) of two monovalent features, [cor] and [dor].
} 
(16)

a.

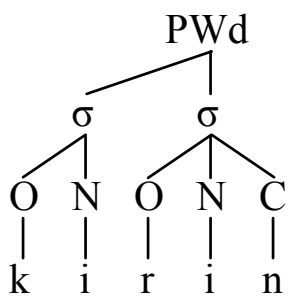

b.

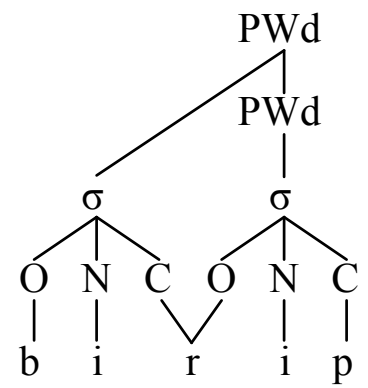

With the possibility of a PWd-internal representation of indefinite bir safely dispensed with, three alternative representations present themselves: (i) bir could form its own PWd; (ii) it could be a free clitic linked directly to the PPh which dominates its host; or (iii) it could be an affixal clitic which is adjoined to the PWd of its host.

As discussed in our previous work (Goad \& White 2004, 2009), the first option, namely that indefinite bir forms its own $\mathrm{PWd}$, is the representation required for other determiners in both Turkish and English, including the numeral bir. Like other determiners in both languages, the numeral bir is stressed. In order for these determiners to bear stress, they cannot be cliticized onto their hosts and instead require their own PWd (and foot) (e.g. Selkirk 1996). See (17). ${ }^{6}$

Independent PWds (Turkish and English):

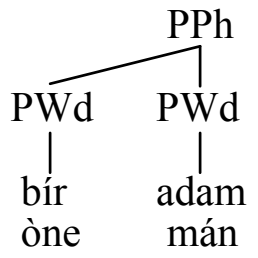

Of the two remaining options, Selkirk (1996) proposes that the representation in (18a), where functional material is linked directly to the PPh of its host, is the one required for English articles. We adopt this position for English but have argued in earlier work (Goad \& White 2004, 2009 ) that Turkish instead employs the representation in (18b); indefinite bir is adjoined to the PWd of its host.

a. Free clitic:

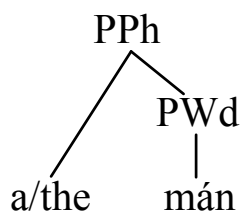

b. Affixal clitic:

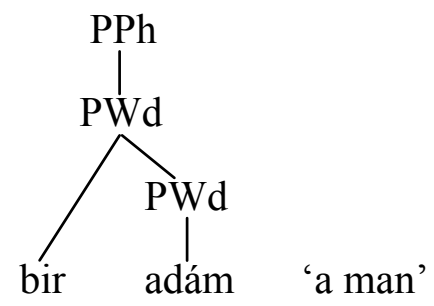

We have motivated (18b) on the basis of word order alternations that are found when bir appears together with an adjective (Goad \& White 2004, 2009). The canonical word order is observed

6 The Turkish example in (17) (as well as others below) has word level stress marked only on bir and not on adam. This is because Turkish speakers disagree on the presence or absence of secondary stress. We have followed Kabak \& Vogel (2001) who state that main stress falls on the final syllable of the leftmost word in the phrase, as this corresponds to the judgments received from the native speaker informants we consulted (see Goad \& White 2009). See Inkelas \& Orgun (2003) for a different view. 
when bir is a numeral (see (19a)); the numeral precedes the adjective because it forms its own PWd. As is evident from (19a), 'one good man' in English has the same structure. However, when bir is an indefinite article, it cannot appear in this position; rather, it must follow the adjective, as in (19b). We have argued that this is directly reflected in prosodic structure: indefinite bir must be cliticized (prefixed) onto the head noun. If indefinite bir were a free clitic, there would be no need for a change in word order, as bir would then link higher in the phrase, like English articles, shown in (19c).

(19)

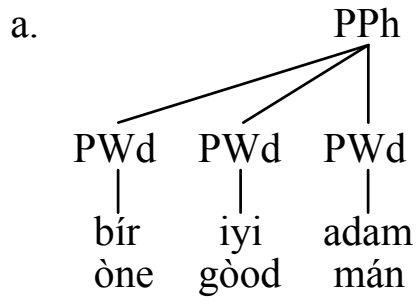

b.

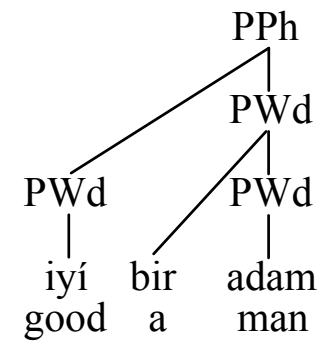

c.

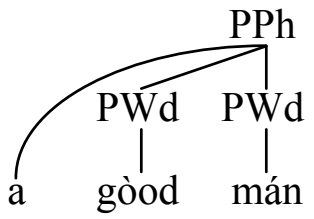

In sum, we have seen that indefinite bir is organized as an affixal clitic. Word order alternations in DPs with adjectives reveal that it cannot have the free clitic representation of English articles, while evidence from syllabification and vowel harmony shows that it cannot be organized internal to the lower PWd. We return to the significance of the lower PWd forming the domain for vowel harmony in section 5, where we discuss the finding that some L2 TurkishEnglish speakers employ harmony in the interlanguage grammars of DPs containing unstressed articles.

\subsection{The syntactic representation of indefinite bir}

Thus far, we have provided a prosodic account of the word order observed in (19b) for Turkish DPs containing adjectives. However, assuming that the underlying order involves the adjective closer to the noun than the indefinite article, the movement required to yield (19b) cannot take place in the phonology proper. In this section, we sketch a syntactic analysis of the Turkish DP and suggest how, by means of post-syntactic local dislocation, indefinite bir ends up in its surface position between the adjective and the noun.

There is considerable debate in the literature concerning the treatment of attributive adjectives. We follow Duffield (1999) who proposes that languages show parametric variation with respect to the position and status of adjective phrases. They may be complements of D, with the head Adj taking NP as its complement; they may occur in Spec, either as specifier of some functional head or in Spec, NP; finally, they may be adjuncts. Because ordering of adjectives is relatively free in Turkish, we assume that they are adjuncts in this language, as illustrated in (20).

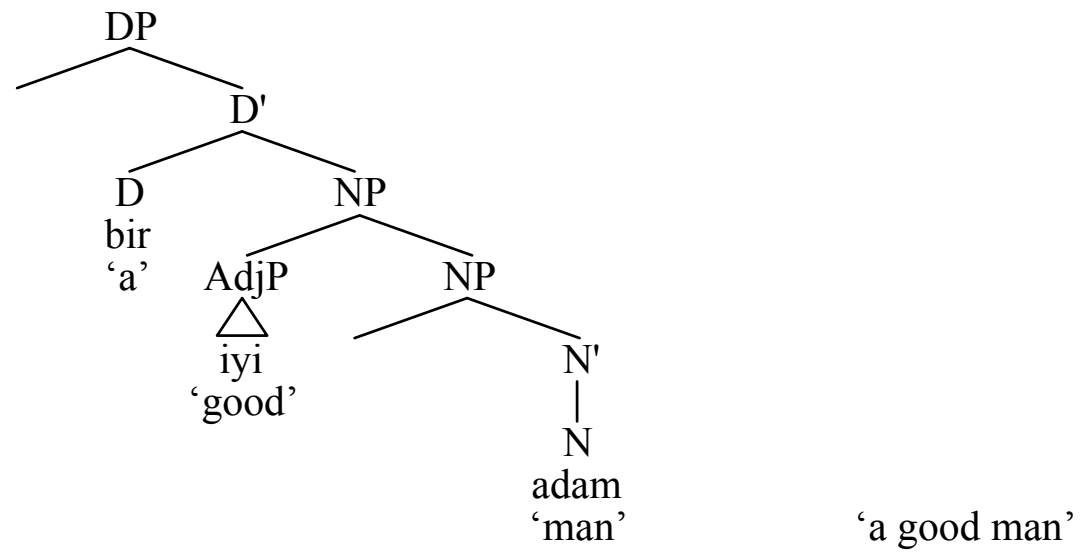


We derive the actual word order (adjective article noun) by means of Embick \& Noyer's (2001) proposal for post-syntactic merger, occurring at PF, which is intended to account for situations where there is a mismatch in ordering between the structure generated by the syntax and actual phonological form. In particular, Embick \& Noyer propose two kinds of PF movement, namely lowering and local dislocation, the second of which is of concern here.

Local dislocation requires linear precedence and adjacency and takes place at or after Vocabulary Insertion. We depart from Embick \& Noyer in a couple of crucial respects: (i) AdjPs are adjuncts rather than complements, at least in Turkish; ${ }^{7}$ (ii) AdjPs are late adjoined (after spell out of the DP). As a result of (ii), the determiner and the noun are string adjacent at PF, prior to adjunction of the AdjP, so local dislocation can take place. ${ }^{8}$ Local dislocation allows [bir+N] to form a unit (a morphological word). This, in turn, allows for two possible prosodifications of bir: as an affixal clitic or PWd-internally. While Turkish employs the first representation, we will see that the interlanguage grammar allows both options.

We assume that local dislocation of indefinite bir is motivated by its being marked as [+bound] in the Vocabulary. We leave open the question of where stressed bir (and other numerals) are generated in the syntax. Even if the numeral bir occurs in the same syntactic position as indefinite bir, namely in D (see 20)), it will not be subject to local dislocation because it is not [+bound] and, thus, it can form an independent PWd in the phonology. Similarly, in English, there is no motivation for local dislocation, as English articles are not bound. Accordingly, they are prosodified as free clitics (when unstressed) or an independent PWds (when stressed).

In sum, it is the [+bound] status of indefinite bir that motivates PF movement and, in turn, leads to the adjunction representation in $(18 b) /(19 b)$.

\section{Previous findings on L2 Turkish articles}

In previous research (Goad \& White 2009), we argued, in accordance with the PTH, that Turkish-speaking learners of English often fail to achieve the target representation for articles in (18a), instead adopting the L1-based representations in (17) and (18b). This generalization was reached using data collected from 18 learners at low $(n=9)$, intermediate $(n=7)$ and advanced $(n=2)$ levels of proficiency. The task involved elicited production, where subjects had to describe a sequence of pictures telling a story. Subjects were taped and the data were subsequently phonetically transcribed and coded for several syntactic and phonological measures.

Results from DPs of the shape article + singular count noun showed that omission of articles was attested for all of the low proficiency subjects and three of the intermediates, ranging from $20 \%$ to $80 \%$ of their article contexts. ${ }^{9}$ All subjects aside from two (one intermediate and one advanced) produced a sizeable proportion of stressed articles, ranging from $15 \%$ to $40 \%$ of their productions. We argued that omission and stressing are a consequence of learners having difficulty building the appropriate representation for English articles, namely the free clitic structure in (18a). Omission avoids the problem altogether, while stressing results in the article forming its own PWd, thereby employing the same representation required for other stressed determiners, as shown in (17).

7 Embick \& Noyer assume that AdjP is the complement of D. This is in part because in the language they are analysing, namely Bulgarian, the article occurs as a suffix on the first head after the D position, i.e. on the first adjective, and only on the noun if there are no adjectives. This is accounted for in terms of lowering, a post-syntactic operation which targets heads. In contrast, Turkish indefinite bir always occurs immediately to the left of the noun regardless of how many adjectives are present, implicating a different structure.

8 For related proposals concerning local dislocation of tense onto the verb, which can ignore adverbial adjuncts, see Bobaljik (1995), Ochi (1999) and Skinner (in preparation).

9 The restriction to singular count nouns was made for syntactic reasons: bare NPs are disallowed in singular count noun contexts in English; thus, ungrammatical article omission can be readily determined. 
Concerning target-like unstressed articles, seven subjects (the two advanced and five of the intermediates) produced a majority of DPs with unstressed articles, ranging from $61 \%$ to $87 \%$ of their article productions, and all of the other subjects (aside from one low proficiency subject) produced unstressed articles at least $16 \%$ of the time. In most contexts where unstressed articles are produced, it is impossible to determine whether L2 speakers have acquired the target representation in (18a) or whether they have instead transferred into English the affixal clitic representation in (18b).

English DPs containing adjectives, however, can help to determine the interlanguage representation of unstressed articles. If subjects have acquired the appropriate representation for prosodifying articles as free clitics, no problem should arise in the context of adjectives. If, on the other hand, they represent articles as affixal clitics, the PTH predicts an asymmetry in suppliance of unstressed (target-sounding) articles in contexts with and without adjectives. In particular, unstressed articles should be supplied less frequently in DPs with adjectives than in DPs without adjectives, resulting in a higher incidence of omission or stressing of articles in the former context. ${ }^{10}$ This is because in the affixal clitic representation, articles must prefix onto the head noun, something which cannot be achieved if the article directly precedes an adjective, as in the illicit (21) (compare with (19b)).

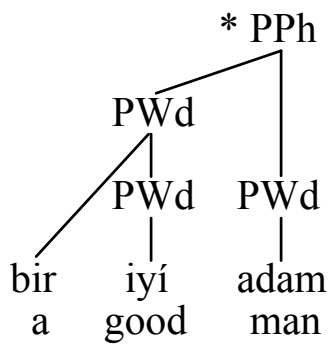

In the experiment described above, six of the 13 subjects who produced sufficient adjectives for an analysis to be possible showed an asymmetry in performance depending on whether or not an adjective was present; presence of adjectives led to a higher incidence of non-target-like articles, suggesting that these learners are transferring the Turkish representation for indefinite bir in (18b) into English. Further, the number of subjects who showed no significant contingency between presence of an adjective and target-like production of articles increased as target-like performance on articles in DPs without adjectives increased. On the basis of these findings, we concluded that more proficient subjects have acquired $(n=3)$ or are in the process of acquiring $(n=3)$ the target representation for English articles in $(18 a)$.

In sum, from our earlier work (Goad \& White 2009), we have seen that Turkish-speaking L2ers employ three representations for overt articles in English: (i) they may stress articles, indicating that the article is organized into its own PWd independent of the PWd of the base to which it attaches, as in (17); (ii) they may show significantly worse suppliance of target-like (unstressed) articles in DPs with adjectives than in DPs without adjectives, indicating that the article is organized as an affixal clitic, as in the L1 grammar (see (18b)); or (iii) they may show no asymmetry in DPs with and without adjectives and display overall high suppliance of unstressed articles in both contexts, indicating that the article is represented as it is in the target grammar (see (18a)). In the following sections, we explore a fourth possibility, that the article may be organized internal to the PWd of its base, something that is not attested for bir in the L1 grammar, but is observed for right-edge morphology, as mentioned in section 3 .

10 If L2ers adopt the [+bound] representation of indefinite bir for English articles, this would, in principle, permit local dislocation followed by late adjunction of the adjective (see section 3.5). However, the result would be an illicit word order in English (*adj art N). Hence, there is a conflict between the post-syntactic structure and the surface L2 word order which L2ers resolve by dropping articles in front of adjectives. Alternatively, if L2ers have understood from English word order in DPs with adjectives that articles are [-bound], in the absence of the required free clitic structure, they resort to the representation in (17) and thereby stress articles in front of adjectives. 


\section{Interlanguage representation of articles revisited}

\subsection{Predictions}

As discussed in section 3, Turkish is a language with vowel harmony operating within the domain of the lower PWd; and while the focus of most research is on rightward spread from root-final vowels to suffixes, leftward spread is also observed targeting epenthetic vowels in loanwords. If Turkish-speaking L2ers were to display leftward harmony from root-initial vowels to articles in their English, e.g. /ðə mæn/ $\rightarrow$ [ð $\varepsilon$ mæn] 'the man', this would indicate that articles must be organized into the PWd of their host, as in (22a), and not outside, as in any of the possibilities in $(22 b-d)$. In other words, vowel harmony is inconsistent with all three representations that we have previously found Turkish speakers to employ in their interlanguage grammars, namely representation as an affixal clitic, like Turkish indefinite bir (22b), representation as a free clitic, like articles in English (22c), or representation as stressed, like other determiners in both Turkish and English (22d).

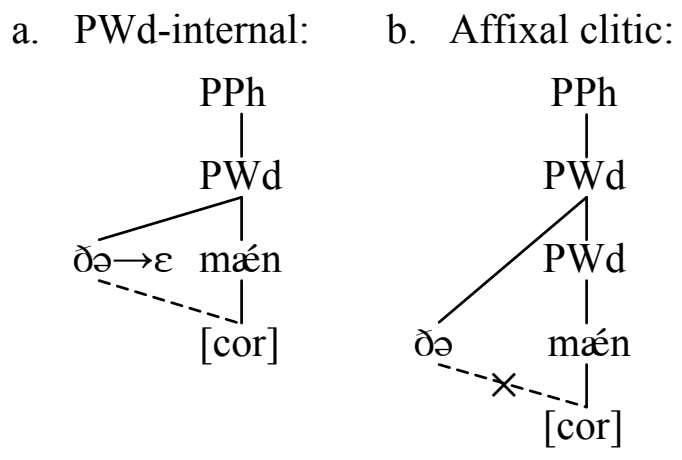

c. Free clitic: d. Stressed article:
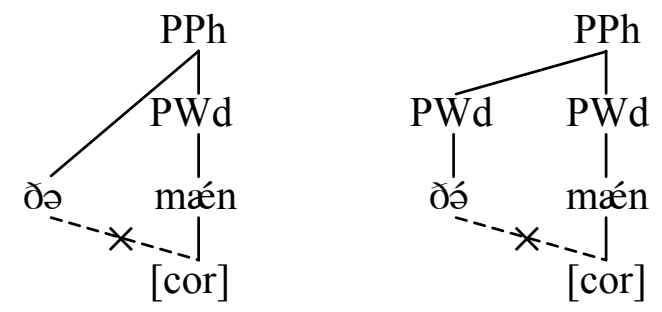

If harmony is revealing of prosodic structure, then consistent with (22a), we expect harmony to be confined to DPs that do not contain adjectives, in which the article is unstressed. Further, there should be no definite/indefinite asymmetry. We elaborate on each of these predictions below.

Concerning stress, recall from section 3.4 that stressed articles form independent PWds. If harmony is confined to single PWds, then no harmony is expected to operate between an article and the following lexical item, whether it is a noun, shown here in (22d), or an adjective.

Turning next to DPs with adjectives, again, if harmony can only apply when an article and following lexical item are inside a single PWd, then the only representation that could permit harmony is that in (23a). However, this representation is illicit for the same reason that (23b) (and (21), discussed above) is ruled out: in both cases, the article is prefixed onto the immediately adjacent adjective, not onto the head noun as required. Since the only licit structure for DPs containing unstressed articles and adjectives is the target representation in (23c) and since in this representation the article and following adjective are not contained inside the same PWd, no vowel harmony is expected to operate between articles and adjectives. 
a. PWd-internal:

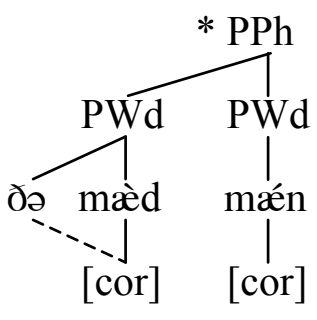

'the mad man' b. Affixal clitic:

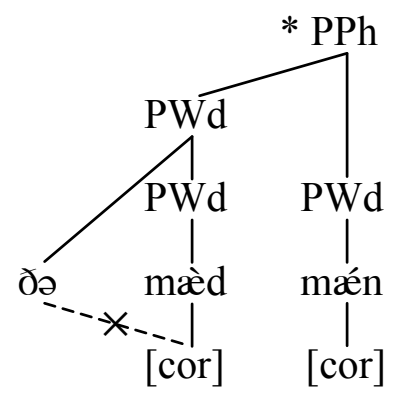

c. Free clitic:

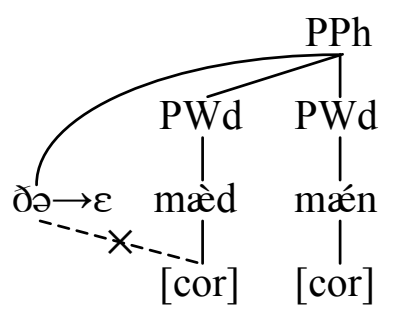

Finally, asymmetries between definites and indefinites are not expected under the PTH, even though Turkish is a language that only contains an indefinite article. Once speakers are aware that English employs both definite and indefinite articles, the PTH predicts that - prosodically both articles should pattern together. This is because, in the unmarked case, languages with two articles prosodify them in the same fashion (stress aside). This should therefore be the starting point for Turkish learners of English. As we will see shortly, the first two predictions are largely borne out. The third is not; this will be taken up in detail in the discussion section.

\subsection{Subjects}

We report here on six subjects (T3, T4, T6, T8, T13, T17) drawn from the 18 participants who took part in the elicited production task in the Goad \& White (2009) study discussed above. ${ }^{11}$ All six subjects had learned some English in school (in Turkey). At the time of testing, all were enrolled in post-secondary education and four (T3, T4, T8, T17) were taking an English course. Two were assessed (by means of a cloze test and self-report) as low proficiency (T4, T17), three as intermediate (T3, T8, T13) and one as advanced (T6). Three subjects (T3, T4, T6) were living in Montreal and were tested there while three others (T8, T13, T17) were living in Istanbul and were tested there. The basis of inclusion in the current analysis is: (a) that it is possible to determine a default vowel for one or both articles (see below); and (b) that vowel harmony is observed at least $15 \%$ of the time in DPs containing unstressed definite articles and no adjectives. ${ }^{12}$

\subsection{Determination of vowel harmony}

Recall from section 3.1 that Turkish displays both backness and rounding harmony. Thus, examination of possible harmony in interlanguage outputs was confined to these two dimensions. Acoustic measurements (F1 and F2 values) of the vowels in the article and first vowel of the following lexical item (adjective or noun) were undertaken. The vowels were then narrowly transcribed using this information as well as the perceptual impressions of the transcriber, a native speaker of English with extensive training in phonetic transcription and acoustic analysis.

Before an assessment could be made as to whether or not a given form displayed harmony, it was necessary to determine the default (underlying) place of the article vowels for every subject. This was done by examining the vowel quality for each article (on the front-back and rounding dimensions; height was ignored) in contexts which, under any analysis, do not display harmony. When, for a given subject, the quality of the vowel in an article varied greatly on the front-back

11 Of the remaining 12 subjects, seven show no vowel harmony (5\% or less overall). For three subjects, we cannot reliably determine the default vowel for either article, a necessary condition in order to examine the nature of any vowel harmony pattern that may be present (see section 5.3 below). The remaining two subjects produced too few unstressed articles to undertake an analysis.

12 The restriction to definite articles will be explained in section 5.5.1. 
dimension (50\%-66\% variance) ${ }^{13}$ it was impossible to determine the default vowel in that particular case. When the quality of the vowel was relatively consistent (ranging from $69 \%$ $100 \%$; average $82 \%$ ), we considered it possible to determine the default vowel. The results are summarized in Table 1.

\begin{tabular}{|c|c|c|}
\hline & Definite article & Indefinite article \\
\hline T3 & central & cannot be determined \\
\hline T4 & front & front \\
\hline T6 & central & front \\
\hline T8 & central & front \\
\hline T13 & central & front \\
\hline T17 & central & front \\
\hline
\end{tabular}

Table 1. Default place for vowel in each article

As is evident in Table 1, the default vowel is usually not the same for both articles. In the case of the definite article, it is central for all subjects except T4; the quality of the vowel is typically [i] or [ə] (variation is observed both within and across subjects). The default vowel in the indefinite article is front for all subjects for whom this can be determined, typically [I], [e] or $[\varepsilon]$ in quality. We believe that this difference in preferred default vowel stems from English orthographic conventions, specifically, that orthographic $a$ is often pronounced as a front vowel, [ei], notably in the letter $A$, while orthographic $e$ is often pronounced as a schwa-like vowel ([ə] or [i]). In the absence of native speaker input, any orthographic influence will be particularly difficult to overcome. ${ }^{14}$

In order to examine how harmony is manifested in the interlanguage grammar, we focus principally on the front-back dimension, as harmony on this dimension was much more commonly attested than harmony on the rounding dimension. Table 2 lists the principal patterns of concern.

\begin{tabular}{|c|c|c|c|c|}
\hline $\begin{array}{c}\text { Pattern } \\
\text { number }\end{array}$ & $\begin{array}{c}\text { Default article } \\
\text { vowel }\end{array}$ & $\begin{array}{c}\text { Surface article } \\
\text { vowel }\end{array}$ & $\begin{array}{c}\text { First vowel in } \\
\text { following lexical item }\end{array}$ & Harmony \\
\hline 1 & front & front & central & no \\
\hline 2 & front & front & back & no \\
\hline 3 & front & central & central & yes \\
\hline 4 & front & central & back & yes \\
\hline 5 & front & front & front & consistent \\
\hline 6 & central & central & front & no \\
\hline 7 & central & front & front & yes \\
\hline 8 & central & back & back & yes \\
\hline 9 & central & central & central & consistent \\
\hline 10 & central & central & back & consistent \\
\hline
\end{tabular}

Table 2. Vowel harmony patterns on the front-back dimension

13 In non-harmony contexts, article vowels were virtually never produced as rounded.

14 According to Öner Ozçelik (p.c.), the vast majority of English instructors in Turkey are non-native speakers of English. 
We begin with contexts where no harmony is observed. When the default vowel in an article is front and it surfaces intact when the first vowel in the following lexical item is central or back, clearly no harmony has taken place (patterns 1-2). The same conclusion holds when the default vowel in an article is central and it surfaces as such before a front vowel (pattern 6).

Turning to harmony contexts, harmony has clearly taken place when a default front vowel centralizes before a central vowel (pattern 3); when a default central vowel fronts before a front vowel (pattern 7); and when a default central vowel backs before a back vowel (pattern 8). What is less obvious is why we have considered pattern 4 as displaying harmony: a default front vowel centralizes before a back vowel. Our reasoning is as follows.

Although Turkish displays harmony on the front-back dimension, we do not necessarily expect harmony to manifest itself in exactly the same way in the interlanguage grammar. This is because there is a tension between the L1 grammar with true front-back harmony and the target grammar which has none. For example, if a subject whose default indefinite vowel is / $/$ / were to turn this vowel into a back vowel when followed by a noun whose first vowel is back, the result would be an output which is significantly distant from the target form, e.g. /I bowt/ $\rightarrow$ [u bowt], [ $v$ bowt] or [u bowt] 'a boat'. Harmony of this type was never attested in our data. In fact, back vowels in articles were largely avoided. What we find instead is a compromise: in cases where the default vowel is front and the first vowel of the following lexical item is back, harmony involves retracting the intended front vowel into the central region of the vowel space,

e.g. /I bowt/ $\rightarrow$ [i bowt] 'a boat'. This is clearly assimilatory (it involves harmony), but in auditory terms, the vowel is not much displaced from the subject's target vowel.

Turning finally to the 'consistent' patterns in Table 2, pattern 5 (front $\rightarrow$ front $/$ front) and pattern 9 (central $\rightarrow$ central / _ central) are labelled as such because they are compatible with a grammar that displays harmony, as well as with one that does not. The remaining pattern, pattern 10 (central $\rightarrow$ central / back), is labelled as consistent because, as mentioned above, we do not expect an interlanguage English grammar with harmony to turn a central vowel in an article into a back vowel. Indeed, central $\rightarrow$ back / _ back (pattern 8) was only attested four times in our data, something which we return to below.

Turning briefly to rounding harmony, this type of harmony was quite rare. The same explanation we provided for the avoidance of harmony-derived back vowels holds here: adding rounding to the vowel in an article significantly alters the acoustic signal and is thus perceived as far from the target. Because rounding harmony was quite rare, in the counts provided below (section 5.5), harmony on the front-back dimension and harmony on the rounding dimension have been collapsed. Accordingly, for a form displaying rounding harmony to be included in the counts, it had to display rounding harmony independent of backness harmony. For example,

$/ \mathbf{i} / \rightarrow[\mathrm{u}] /[\mathrm{u}]$ was classified as rounding harmony, while $/ \mathrm{I} / \rightarrow[\mathrm{u}] /{ }_{[\mathrm{u}]}$ was not, as it also displays backness harmony (pattern 4).

In the following section, we provide a formal analysis of harmony which stems from these observations.

\subsection{Formalizing harmony}

Recall from section 3.1 that Turkish has both backness and rounding harmony. Given the featural specifications for (high) vowels in (24a), harmony on the front-back dimension involves spreading of [cor] and [dor] while harmony on the rounding dimension involves spreading of [lab]. However, we have just seen that in the interlanguage grammar, harmony is largely confined to alternations between front and central; that is, article vowels rarely surface as back or round. It would appear, then, that [dor] and [lab] do not spread in the interlanguage grammar and that spreading is confined to [cor] and whatever feature expresses centrality. 
(24)

a. Turkish:

\begin{tabular}{|c|c|c|c|}
\hline \multicolumn{2}{|c|}{ [cor] } & \multicolumn{2}{c|}{ [dor] } \\
\hline & {$[\mathrm{lab}]$} & & {$[\mathrm{lab}]$} \\
\hline $\mathrm{i}$ & $\ddot{\mathrm{u}}$ & $\mathrm{u}$ & $\mathrm{u}$ \\
\hline
\end{tabular}

b. English:

\begin{tabular}{|c|c|c|}
\hline$[$ cor $]$ & & {$[\mathrm{dor}] /[\mathrm{lab}]$} \\
\hline $\mathrm{i}$ & $\mathrm{i}$ & $\mathrm{u}$ \\
\hline
\end{tabular}

Concerning the latter, research on vowel features has shown that central vowels rarely transmit their centrality and, instead, acquire place features from other vowels; this suggests that they are inherently placeless (e.g. Schane 1984; Kaye, Lowenstamm \& Vergnaud 1985; Goad 1993; Clements \& Hume 1995). Accordingly, there is no evidence for a feature [central] and the SPE proposal (Chomsky \& Halle 1968) that central vowels are [+back] is empirically unsupported. This is reflected in the specifications for English vowels in (24b) and will clearly have consequences for how harmony operates in the interlanguage grammar: only [cor] can spread; assimilation to centrality must be formally expressed through some other means, namely through delinking (feature loss). While this may appear to be a weakness, empirical support that centralization involves delinking rather than spreading will emerge from a closer look at pattern 4 in Table 2. Further, support for a distinction between spreading and delinking will arise from an examination of asymmetries in the treatment of definite and indefinite articles (see section 6).

We begin by comparing patterns 7 and 3, both of which are categorized in Table 2 as involving harmony. Pattern 7 in (25a) involves spreading of [cor] from the leftmost front vowel in the root to an inherently placeless vowel in the article, within the domain of the PWd. The inverse case, pattern 3 in (25b), involves delinking of [cor] from the article vowel, leading to agreement for place features.

Vowel harmony:

a. Pattern 7:

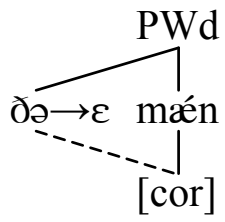

'the man' b. Pattern 3:

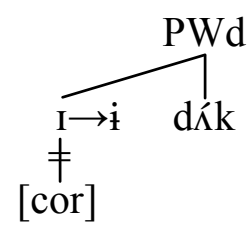

'a duck'

In short, vowel harmony formally involves feature agreement which arises either by spreading [cor] to the article vowel or by delinking [cor] from the article vowel.

Concerning the cases we have described as 'consistent' in Table 2, patterns 5 and 9 are the inverse of those in (25) as concerns the segmental profile of the determiner. In a grammar with harmony, pattern 5 involves vacuous spreading as both trigger and target bear [cor] in the input; see (26a). In pattern 9, there is similarly already feature agreement in the input. In this case, though, there is no feature present to spread or delink; see (26b).

Consistent:

a. Pattern 5:

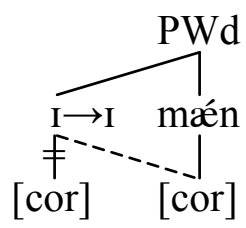

b. Pattern 9:

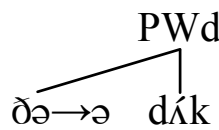

'the duck'

We turn finally to cases where the initial vowel in the root is back. The input for pattern 8 is formally identical to that for pattern 7 (in (25a)). However, as discussed earlier, there is no [dor] spread in the interlanguage grammar: only four cases of pattern 8 are attested in the entire database. Thus, we consider spreading of [dor] as in (27a) to be ungrammatical. Inputs of this 
shape instead follow pattern 10 ; see (27b). In this case, there is no feature on the noun that can spread nor any feature on the article to delink; thus, these forms are consistent with a grammar that displays harmony involving spreading and delinking of [cor].

[dor] spread unattested:

a. Pattern 8:

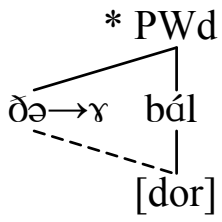

'the ball' b. Pattern 10:

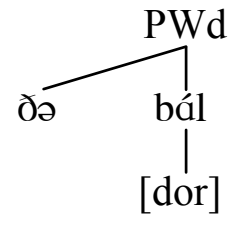

'the ball'

Because [dor] cannot spread, in the case of a [cor] article followed by a [dor]-initial noun as in pattern 4, a completely harmonic output cannot be derived. However, delinking [cor] yields an output with vowels that are phonetically closer (i.e., front-back becomes central-back), and since [cor] delinking is one of the processes already employed in the grammar to formally express harmony, it applies here, yielding partial agreement; see (28). In fact, the only way to arrive at this type of intermediate output is for central vowels to be unspecified for place features and for the process to involve delinking. A central-vowelled output cannot arise from a [cor] vowel assimilating to a [dor]-initial noun in a principled way through spreading.

\section{Pattern 4:}

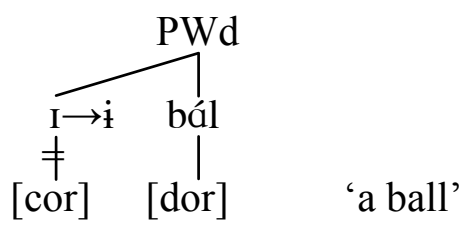

In sum, harmony involves two separate agreement processes, spreading in the case of [cor]initial roots and delinking in the case of [cor] articles. While this may seem formally cumbersome, it leads to a principled account of partial agreement in the case of pattern 4 . In addition, the need for both spreading and delinking will be supported when we examine differences in the learners' treatment of DPs with definite versus indefinite articles.

With this background in mind, we turn now to the results.

\subsection{Results}

We confine our analysis to cases where an overt article is supplied, either stressed or unstressed. In addition to considering definite and indefinite articles with singular count nouns, we include definite articles with mass nouns and plural count nouns. (The incidence of mass and plural nouns is quite low, in part reflecting the fact that the story was originally designed to elicit singular count nouns.) The average number of relevant DPs produced per subject was 94, ranging from 39 to $154.15,16$

15 For T3, this calculation includes definite DPs only; recall from Table 1 that it was impossible to determine the default vowel for the indefinite article for this subject.

16 Aside from the inclusion of definite articles with mass nouns and plural count nouns, the totals in this paper do not always align with those in Goad \& White (2009) as two types of adjective constructions have been removed for the following reasons: (i) cases where the prosodic structure has been disrupted because there is a pause or filler between the adjective and noun; (ii) adjective constructions of the shape 'the $\mathrm{X}$ one'. In an example like 'the blue one', primary stress occurs on 'blue' and 'one' can be cliticized onto it. Since 'blue' is the prosodic head, the article could be organized internal to the PWd of 'blue' and vowel harmony could legitimately apply. 
Recall from section 5.1 that, for prosodic reasons, vowel harmony should only be observed if the article is unstressed and if there is no adjective intervening between the article and noun. Further, no asymmetry is expected to hold between definites and indefinites. In order to test these predictions, the following factors were examined separately: definite vs. indefinite article; presence vs. absence of adjective (in unstressed article contexts); stressed vs. unstressed article.

\subsubsection{DPs containing unstressed articles and no adjectives}

Table 3 shows the incidence of vowel harmony in cases where an unstressed article precedes the noun directly. Harmony is expected to apply in this construction when subjects have organized the article inside the PWd of the base (as in (22a)). In the case of definite DPs, the column labelled VH reveals that harmony applies unambiguously from $16 \%-36 \%$ of the time. This range increases to $52 \%-72 \%$ when the data in the Consistent column are taken into consideration. Recall that consistent forms are compatible both with a grammar that displays harmony and with one that does not. In a grammar with harmony, consistent forms involve vacuous application of this process (e.g., spreading [cor] to a vowel which is already specified for $[$ cor] $)$.

\begin{tabular}{|c|c|c|c|c|c|c|}
\hline & \multicolumn{3}{|c|}{ Definite articles } & \multicolumn{3}{|c|}{ Indefinite articles } \\
\hline & $\mathrm{VH}$ & Consistent & No VH & VH & Consistent & No VH \\
\hline $\mathrm{T} 3$ & $\begin{array}{c}12 / 55 \\
22 \%\end{array}$ & $\begin{array}{c}26 / 55 \\
47 \%\end{array}$ & $\begin{array}{c}17 / 55 \\
31 \%\end{array}$ & \multicolumn{3}{|c|}{$\mathrm{n} / \mathrm{a}$} \\
\hline $\mathrm{T} 4$ & $\begin{array}{l}9 / 25 \\
36 \%\end{array}$ & $\begin{array}{l}4 / 25 \\
16 \%\end{array}$ & $\begin{array}{c}12 / 25 \\
48 \%\end{array}$ & $\begin{array}{l}0 / 1 \\
0 \%\end{array}$ & $\begin{array}{l}0 / 1 \\
0 \%\end{array}$ & $\begin{array}{c}1 / 1 \\
100 \%\end{array}$ \\
\hline T6 & $\begin{array}{l}9 / 48 \\
19 \%\end{array}$ & $\begin{array}{c}24 / 48 \\
50 \%\end{array}$ & $\begin{array}{c}15 / 48 \\
31 \%\end{array}$ & $\begin{array}{l}6 / 13 \\
46 \%\end{array}$ & $\begin{array}{l}2 / 13 \\
15 \%\end{array}$ & $\begin{array}{l}5 / 13 \\
39 \%\end{array}$ \\
\hline T8 & $\begin{array}{c}15 / 92 \\
16 \%\end{array}$ & $\begin{array}{ll} & 40 / 92 \\
& 44 \% \\
& \\
\end{array}$ & $\begin{array}{c}37 / 92 \\
40 \%\end{array}$ & $\begin{array}{c}4 / 8 \\
50 \%\end{array}$ & $\begin{array}{c}1 / 8 \\
12 \%\end{array}$ & $\begin{array}{c}3 / 8 \\
38 \%\end{array}$ \\
\hline $\mathrm{T} 13$ & $\begin{array}{c}18 / 61 \\
30 \%\end{array}$ & $\begin{array}{cc} & 25 / 61 \\
& 40 \% \\
& \\
\end{array}$ & $\begin{array}{c}18 / 61 \\
30 \%\end{array}$ & $\begin{array}{l}0 / 6 \\
0 \%\end{array}$ & $\begin{array}{c}1 / 6 \\
17 \% \\
\end{array}$ & $\begin{array}{r}/ 6 \\
\\
\quad 83 \% \\
\end{array}$ \\
\hline T17 & $\begin{array}{c}12 / 39 \\
31 \%\end{array}$ & $\begin{array}{l}16 / 39 \\
41 \% \\
4\end{array}$ & $\begin{array}{c}11 / 39 \\
28 \%\end{array}$ & $\begin{array}{l}0 / 2 \\
0 \%\end{array}$ & $\begin{array}{l}0 / 2 \\
0 \%\end{array}$ & $\begin{array}{c}2 / 2 \\
100 \%\end{array}$ \\
\hline
\end{tabular}

Table 3. Incidence of VH in DPs of the shape unstressed art $+\mathrm{N}$

Harmony does not apply to definite article vowels $100 \%$ of the time. When it does not take place, we assume that the article is organized outside the lower PWd of its host (as in (22b) or (22c)), so spreading cannot apply nor can delinking be motivated. In other words, L2ers are entertaining more than one possible representation for English articles. We return to this point in the discussion.

The incidence of indefinite DPs with unstressed articles is low for most subjects, so our prediction that there should be no definite-indefinite asymmetry cannot be tested in all cases. T6 and T8 do in fact show harmony with indefinites as well as definites, and in the same proportion 
when consistent data are factored in. Contrary to our prediction, one subject, T13, appears to disallow harmony with indefinites but the number of indefinite contexts is quite low. ${ }^{17}$

In sum, we have seen that harmony applies quite robustly in the grammars of these six subjects, in the case of DPs containing unstressed definite articles. The situation with indefinites is not clear for several of the subjects because of the relative infrequency of unstressed indefinites in their data. We will return to this issue in section 6.

\subsubsection{DPs containing unstressed articles and adjectives}

As discussed above, the only construction where a PWd-internal analysis of the article is possible is DPs containing unstressed articles and no adjectives. Thus, one construction where harmony should not be attested is in DPs containing unstressed articles and adjectives (see (23) above). Table 4 presents the relevant data. The table provides data for definite articles alone as, aside from T8, no subject produced unstressed indefinites in adjective constructions. ${ }^{18}$

\begin{tabular}{|c|c|c|c|}
\hline & \multicolumn{3}{|c|}{ Definite articles } \\
\hline & $\mathrm{VH}$ & Consistent & No VH \\
\hline T3 & $1 / 4$ & $1 / 4$ & $2 / 4$ \\
\hline & $25 \%$ & $25 \%$ & $50 \%$ \\
\hline & & \multicolumn{2}{|c|}{$75 \%$} \\
\hline \multirow[t]{2}{*}{$\mathrm{T} 4$} & $0 / 2$ & $0 / 2$ & $2 / 2$ \\
\hline & $0 \%$ & $0 \%$ & $100 \%$ \\
\hline \multirow[t]{3}{*}{ T6 } & $1 / 5$ & $2 / 5$ & $2 / 5$ \\
\hline & $20 \%$ & $40 \%$ & $40 \%$ \\
\hline & & \multicolumn{2}{|c|}{$80 \%$} \\
\hline \multirow{2}{*}{ T8 } & $1 / 3$ & $0 / 3$ & $2 / 3$ \\
\hline & $33 \%$ & $0 \%$ & $67 \%$ \\
\hline \multirow[t]{3}{*}{ T13 } & $5 / 25$ & $1 / 25$ & $19 / 25$ \\
\hline & $20 \%$ & $4 \%$ & $76 \%$ \\
\hline & & \multicolumn{2}{|c|}{$80 \%$} \\
\hline T17 & $0 / 2$ & $0 / 2$ & $2 / 2$ \\
\hline & $0 \%$ & $0 \%$ & $100 \%$ \\
\hline
\end{tabular}

Table 4. Incidence of VH in DPs of the shape unstressed art $+\operatorname{adj}+\mathrm{N}$

Aside from T13, no subject produced more than one case of the unexpected VH pattern. However, since these five subjects produced so few adjectives with unstressed articles overall, it is difficult to make meaningful comparisons with the data in Table $3 .{ }^{19}$ Let us therefore focus on T13.

T13 produces $5 / 25$ cases of the unexpected pattern. This represents $20 \%$ of his data overall and, thus, does not appear to be much different from the $30 \%$ of his data that display harmony in DPs with unstressed definite articles and no adjectives (Table 3 ). There is, however, a very important difference between these two constructions that is revealed in Table 5. A much lower proportion of articles in DPs without adjectives forbids harmony (30\%) than in DPs with

17 We have nevertheless tentatively grouped the forms in the Consistent and No VH columns together for this subject.

18 T8 produced two examples. The profile observed was: $1 / 2 \mathrm{VH}, 0 / 2$ Consistent, $1 / 2$ No VH.

19 Nevertheless, we have tentatively grouped the Consistent and No VH forms of T3 and T6 together in Table 4 as the profile is suggestive of a grammar without vowel harmony in DPs of this shape. 
adjectives (76\%). If we leave the Consistent forms aside, the ratio of $\mathrm{VH}$ to No $\mathrm{VH}$ is $1: 1$ in the former case and 1:3.8 in the latter.

\begin{tabular}{|c|c|c|c|c|}
\hline \multirow{4}{*}{} & \multicolumn{3}{|c|}{$\begin{array}{c}\text { Unstressed Def + N } \\
\text { (Table 3) }\end{array}$} & \multicolumn{2}{|c|}{$\begin{array}{c}\text { Unstressed Def + Adj + N } \\
\text { (Table 4) }\end{array}$} \\
& VH & No VH & VH & No VH \\
\hline T13 & $18 / 61$ & $18 / 61$ & $5 / 25$ & $19 / 25$ \\
& $30 \%$ & $30 \%$ & $20 \%$ & $76 \%$ \\
& \multicolumn{2}{|l|}{$1: 1$} & & \multicolumn{2}{|c|}{$1: 3.8$} \\
\hline
\end{tabular}

Table 5. DPs with unstressed definite articles containing vs. not containing adjectives

There is a significant contingency between presence of an adjective and absence of vowel harmony for $\mathrm{T} 13\left(\chi^{2}=4.02, \mathrm{df}=1, \mathrm{p}=.045\right)$. This contingency, in turn, warrants the conclusion that, for this subject, consistent forms be grouped with VH forms in the case of DPs without adjectives (Table 3 ) and with No VH forms in the case of DPs with adjectives (Table 4). In sum, for T13, the results are in the expected direction, that is, consistent with the representation in (22c).

\subsubsection{DPs containing stressed articles}

We turn finally to DPs containing stressed articles. ${ }^{20}$ Because the article forms its own PWd in this construction, (22d), harmony should not be observed. Table 6 shows the incidence of harmony in DPs of this profile. ${ }^{21}$

20 On the basis of a closer examination of the data, including spectral properties of article vowels, some forms that were coded as stressed in Goad \& White (2009) have been recoded as unstressed harmonic.

21 Table 6 includes DPs both with and without adjectives. The number of adjective cases is as follows (with the number displaying harmony in parentheses): T3: 4 def; T4: 0 def, 0 indef; T6: 0 def, 4 (1) indef; T8: 2 def, 11 (3) indef; T13: 5 def, 1 indef; T17: 0 def, 1 indef. 


\begin{tabular}{|c|c|c|c|c|c|c|}
\hline & \multicolumn{3}{|c|}{ Definite articles } & \multicolumn{3}{|c|}{ Indefinite articles } \\
\hline & VH & Consistent & No VH & VH & Consistent & No VH \\
\hline $\mathrm{T} 3$ & $\begin{array}{l}2 / 15 \\
13 \%\end{array}$ & $\begin{array}{l}5 / 15 \\
33 \% \\
\end{array}$ & $\begin{array}{l}8 / 15 \\
54 \%\end{array}$ & \multicolumn{3}{|c|}{$\mathrm{n} / \mathrm{a}$} \\
\hline $\mathrm{T} 4$ & $\begin{array}{c}1 / 4 \\
25 \%\end{array}$ & $\begin{array}{c}1 / 4 \\
25 \% \\
\end{array}$ & $\begin{array}{c}2 / 4 \\
50 \%\end{array}$ & $\begin{array}{l}0 / 7 \\
0 \%\end{array}$ & $\begin{array}{ll}4 / 7 & \\
57 \% & \\
& 10\end{array}$ & $\begin{array}{c}3 / 7 \\
43 \% \\
\\
\end{array}$ \\
\hline T6 & $\begin{array}{l}0 / 0 \\
0 \%\end{array}$ & $\begin{array}{l}0 / 0 \\
0 \%\end{array}$ & $\begin{array}{l}0 / 0 \\
0 \%\end{array}$ & $\begin{array}{c}1 / 20 \\
5 \%\end{array}$ & $\begin{array}{l}3 / 20 \\
15 \%\end{array}$ & $\begin{array}{c}16 / 20 \\
80 \%\end{array}$ \\
\hline T8 & $\begin{array}{l}0 / 10 \\
0 \%\end{array}$ & $\begin{array}{ll}5 / 10 & \\
50 \% & \\
& 10 \\
\end{array}$ & $\begin{array}{l}5 / 10 \\
50 \% \\
\end{array}$ & $\begin{array}{l}4 / 39 \\
10 \%\end{array}$ & $\begin{array}{l}8 / 39 \\
21 \%\end{array}$ & $\begin{array}{c}27 / 39 \\
69 \% \\
\end{array}$ \\
\hline $\mathrm{T} 13$ & $\begin{array}{l}1 / 12 \\
8 \%\end{array}$ & $\begin{array}{l}6 / 12 \\
50 \%\end{array}$ & $\begin{array}{l}5 / 12 \\
42 \%\end{array}$ & $\begin{array}{c}0 / 21 \\
0 \%\end{array}$ & $\begin{array}{ll}9 / 21 & \\
43 \% & \\
& 10 \\
\end{array}$ & $\begin{array}{c}12 / 21 \\
57 \% \\
\end{array}$ \\
\hline T17 & $\begin{array}{c}1 / 2 \\
50 \%\end{array}$ & $\begin{array}{c}1 / 2 \\
50 \%\end{array}$ & $\begin{array}{l}0 / 2 \\
0 \%\end{array}$ & $\begin{array}{c}0 / 32 \\
0 \%\end{array}$ & $\begin{array}{ll}13 / 32 & \\
41 \% & \\
& 10\end{array}$ & $\begin{array}{l}19 / 32 \\
59 \% \\
0\end{array}$ \\
\hline
\end{tabular}

Table 6. Incidence of VH in DPs containing stressed articles

As can be seen, there are some cases of the unexpected VH pattern, on average $6 \%$ across subjects. However, for all subjects, lack of harmony predominates over harmony, to a much greater extent than with unstressed articles. Further, because of the sizable number of indefinites in DPs of this shape, the pattern can be seen to hold for definite as well as indefinite articles (leaving aside definites for T17 where the numbers are so low).

Table 7 reveals that the difference between DPs with and without stress is robust: the expectation that harmony should be limited to DPs with unstressed articles lacking adjectives (Table 3) and not observed in DPs with stressed articles (Table 6) is largely supported for all subjects. (* indicates those subjects whose DPs containing harmonic unstressed articles are restricted to definite articles; see discussion in section 5.5.1.) 


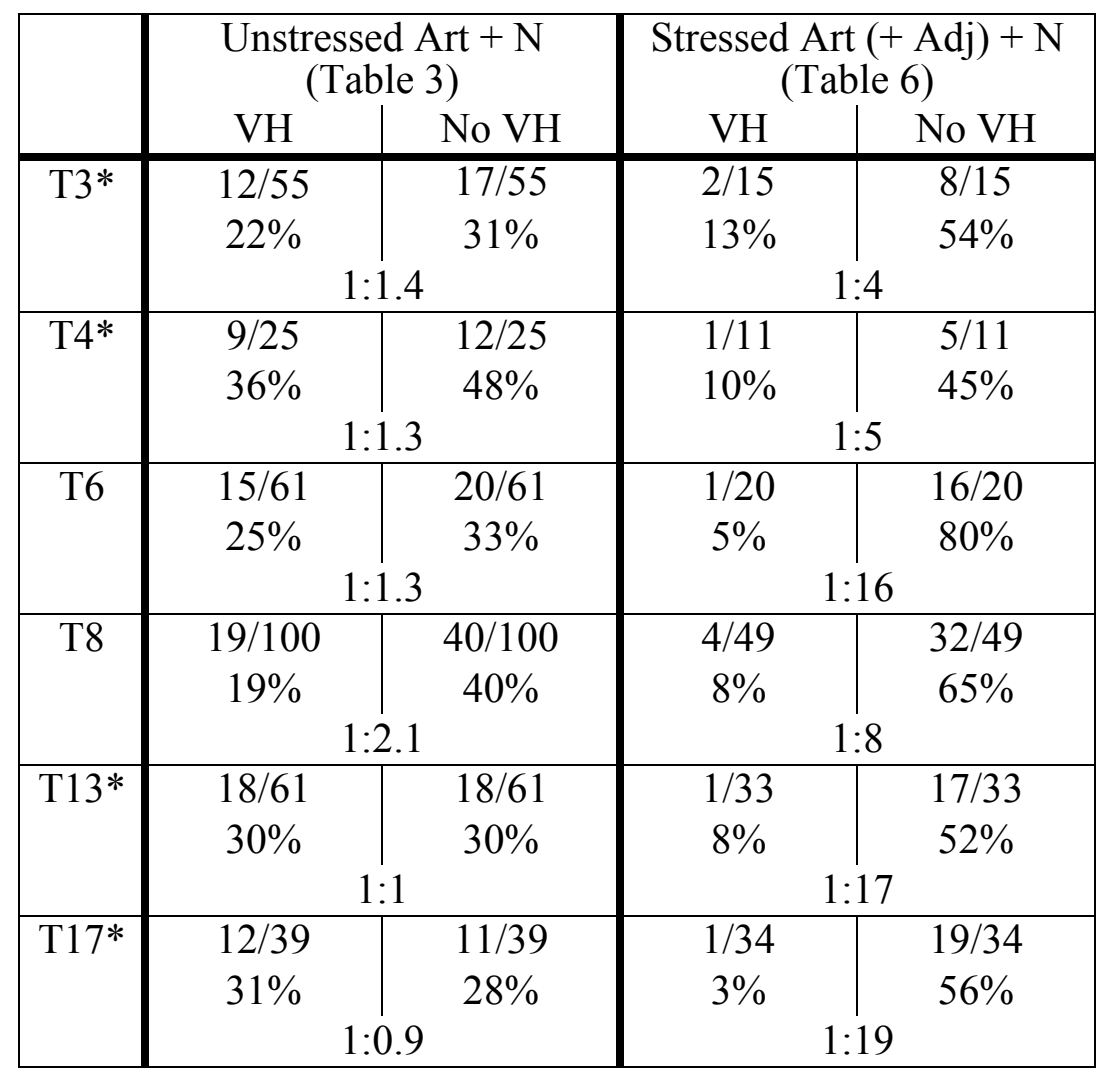

Table 7. DPs with unstressed vs. stressed articles

If we leave the consistent forms aside, the ratio of $\mathrm{VH}$ to No $\mathrm{VH}$ for DPs with unstressed articles is approximately 1:1 (range 1:0.9 to 1:2.1), while that for DPs with stressed articles is much lower, ranging from 1:4 to 1:19. Fisher's exact probability test (two-tailed) reveals a significant association between presence of a stressed article and absence of vowel harmony for four subjects (T6: $\mathrm{p}=.009 ; \mathrm{T} 8: \mathrm{p}=.026 ; \mathrm{T} 13: \mathrm{p}=.002 ; \mathrm{T} 17: \mathrm{p}<.001$ ). This, in turn, warrants the conclusion that, at least for these four subjects, consistent forms be grouped with $\mathrm{VH}$ forms in the case of DPs without adjectives (Table 3) and with No VH forms in the case of DPs with adjectives (Table 6). In sum, the results from DPs with stressed articles are in the right direction, consistent with the representation in (22d) where no harmony is expected.

\section{Discussion}

The results for all three types of DPs are largely consistent with the expectation that harmony should be confined to contexts where the article can be incorporated into the PWd of its host, as in (22a); that is, it should be limited to DPs containing unstressed articles and no adjectives. The low proportion of harmony observed in DPs with stressed articles (Table 6) supports the hypothesis that these articles form their own PWd independent of the PWd of their host, as in (22d). The high proportion of cases where no harmony is observed in DPs with adjectives for T13 (the only subject for whom there are enough data (Table 4)) supports the proposal that this subject is using the target English representation in (22c). The latter is consistent with the conclusion reached in Goad \& White (2009). In fact, considering the results of Goad \& White (2009) and this paper together, five of the subjects under focus (T3, T4, T6, T8, T17) appear to be using the L1-based affixal clitic representation in (22b) alongside the PWd-internal representation in (22a) for unstressed articles and one subject (T13) appears to be using the target 
free-clitic representation in (22c) alongside (22a). Although the subjects under examination have appropriately restricted harmony to those contexts where the article can be organized inside the PWd of its host, the question that nevertheless arises is why they have chosen to use this representation when the L1 affixal clitic representation in (22b) is presumably available through transfer. We offer some possible answers to this question below.

We begin with the quality of the default vowel in the definite and indefinite articles. Recall that, for all speakers, the indefinite article is underlyingly front while, for all except T4, the vowel in the definite article is underlyingly central. As discussed in section 5.4, formally, this means that the indefinite article vowel is specified for place ([cor]) while the definite article vowel is placeless. There are a number of properties that we believe stem from this difference in vowel specification which, in turn, point to an explanation for the PWd-internal representation of unstressed articles.

A closer look at Tables 3 and 6 reveals that speakers prefer different non-target prosodic representations for indefinite and definite constructions; we conjecture that this is largely tied to the presence or absence of place on the article vowel. The relevant information appears in Table 8.22

\begin{tabular}{|c|c|c|c|c|c|c|c|c|}
\hline & \multicolumn{4}{|c|}{ Definite } & \multicolumn{4}{|c|}{ Indefinite } \\
\hline & $\begin{array}{c}\text { Default } \\
\text { vowel }\end{array}$ & $\begin{array}{c}\text { Stressed } \\
(22 \mathrm{~d})\end{array}$ & $\begin{array}{c}\text { Unstressed } \\
\text { with VH } \\
\text { (22a) }\end{array}$ & $\begin{array}{c}\text { Unstressed } \\
\text { no VH } \\
(22 \mathrm{~b} / \mathrm{c})\end{array}$ & $\begin{array}{c}\text { Default } \\
\text { vowel }\end{array}$ & $\begin{array}{c}\text { Stressed } \\
(22 \mathrm{~d})\end{array}$ & $\begin{array}{c}\text { Unstressed } \\
\text { with VH } \\
\text { (22a) }\end{array}$ & $\begin{array}{c}\text { Unstressed } \\
\text { no VH } \\
(22 \mathrm{~b} / \mathrm{c})\end{array}$ \\
\hline $\mathrm{T} 3$ & central & $\begin{array}{l}11 / 66 \\
(17 \%)\end{array}$ & $\begin{array}{l}38 / 66 \\
(57 \%)\end{array}$ & $\begin{array}{l}17 / 66 \\
(26 \%)\end{array}$ & \multicolumn{4}{|c|}{$\mathrm{n} / \mathrm{a}$} \\
\hline $\mathrm{T} 4$ & front & $\begin{array}{c}4 / 29 \\
(14 \%)\end{array}$ & $\begin{array}{l}13 / 29 \\
(45 \%)\end{array}$ & $\begin{array}{l}12 / 29 \\
(41 \%)\end{array}$ & front & $\begin{array}{c}7 / 8 \\
(88 \%)\end{array}$ & $\begin{array}{c}0 / 8 \\
(0 \%)\end{array}$ & $\begin{array}{c}1 / 8 \\
(12 \%)\end{array}$ \\
\hline T6 & central & $\begin{array}{c}0 / 48 \\
(0 \%)\end{array}$ & $\begin{array}{l}33 / 48 \\
(69 \%)\end{array}$ & $\begin{array}{l}15 / 48 \\
(31 \%)\end{array}$ & front & $\begin{array}{l}16 / 29 \\
(55 \%)\end{array}$ & $\begin{array}{c}8 / 29 \\
(28 \%)\end{array}$ & $\begin{array}{c}5 / 29 \\
(17 \%)\end{array}$ \\
\hline T8 & central & $\begin{array}{l}8 / 100 \\
(8 \%)\end{array}$ & $\begin{array}{l}55 / 100 \\
(55 \%)\end{array}$ & $\begin{array}{l}37 / 100 \\
(37 \%)\end{array}$ & front & $\begin{array}{l}28 / 36 \\
(78 \%)\end{array}$ & $\begin{array}{c}5 / 36 \\
(14 \%)\end{array}$ & $\begin{array}{l}3 / 36 \\
(8 \%)\end{array}$ \\
\hline T13 & central & $\begin{array}{c}7 / 68 \\
(10 \%)\end{array}$ & $\begin{array}{l}43 / 68 \\
(63 \%)\end{array}$ & $\begin{array}{l}18 / 68 \\
(27 \%)\end{array}$ & front & $\begin{array}{l}20 / 26 \\
(77 \%)\end{array}$ & $\begin{array}{l}0 / 26 \\
(0 \%)\end{array}$ & $\begin{array}{c}6 / 26 \\
(23 \%)\end{array}$ \\
\hline $\mathrm{T} 17$ & central & $\begin{array}{l}2 / 41 \\
(5 \%)\end{array}$ & $\begin{array}{l}28 / 41 \\
(68 \%)\end{array}$ & $\begin{array}{l}11 / 41 \\
(27 \%)\end{array}$ & front & $\begin{array}{l}31 / 33 \\
(94 \%)\end{array}$ & $\begin{array}{l}0 / 33 \\
(0 \%)\end{array}$ & $\begin{array}{l}2 / 33 \\
(6 \%)\end{array}$ \\
\hline
\end{tabular}

Table 8. Definite-indefinite asymmetries (DPs without adjectives)

A comparison of the two Stressed columns in Table 8 reveals that the indefinite article often bears stress (55\%-94\% of the time), in contrast to the definite article ( $0 \%-17 \%$ of the time). We conclude from this that the indefinite article can form its own PWd as in (22d) (and indeed that this is the preferred option for most subjects), while something about the definite article prevents this representation.

We believe that the latter stems from the quality of the vowel: in most languages, including English, schwa-like vowels cannot be stressed (e.g. van Oostendorp 1998). In view of this, some structure other than (22d) will be preferred for underlyingly placeless definite articles. Among the alternatives available, we can see from the Unstressed with VH column in Table 8 that, aside from T4 who has a different default vowel, 55\%-69\% of definite articles undergo harmony, indicating a relatively high preference for the PWd-internal representation in (22a).

22 The numerators in the Stressed columns come from Table 6, adjusted to remove adjective cases, in order to allow direct comparison with the information extracted from Table 3. The numerators in the Unstressed columns come from the information in Table 3. 
This preference, we reason, is also tied to the quality of the vowel. Recall from (3) that Turkish has no central (inherently placeless) vowels. That is, Turkish requires vowels to surface with place. If this constraint still holds of the interlanguage grammar but learners have arrived at an underlying representation of the English definite article that is inherently placeless, the most straightforward way for this vowel to acquire place, given the L1 grammar, is through harmony, spreading of [cor] from the root-initial vowel. This, in turn, requires that the article be organized PWd-internally. In short, the PWd-internal representation for the definite article arises in order for this vowel to acquire place. ${ }^{23}$

Turning to indefinite articles, Table 8 reminds us that, in contrast to definite articles, indefinite article vowels are underlyingly [cor]. If harmony applies to give place to article vowels, it would be counter-productive for indefinite articles to undergo harmony: harmony would involve delinking of [cor], leaving the article vowel placeless. Thus, we expect indefinite articles to be organized in some fashion other than through the PWd-internal representation in (22a). Table 8 reveals that indefinites typically surface with stress, indicating a preference for the structure in $(22 \mathrm{~d})$.

We do not fully understand why this particular structure is favoured: although we have just seen that there is often a relationship between absence of place and absence of stress, the opposite does not hold. Recall, however, that the source of the difference in default vowel quality in definites and indefinites may be tied to orthography, since the letter $A$ is often pronounced as long [ei] in English. If L2ers further understand that long vowels attract stress in English (as in many other languages), this may well lead to a preference for the independent PWd representation for indefinite articles.

Finally, although the number of unstressed indefinites is low for most subjects, we can nevertheless see that two subjects, T6 and T8, do show harmony in DPs of this shape. Since the article vowel has place underlyingly in this case, what motivates the application of harmony? It appears that once the grammars of these subjects permit harmony in definite article + noun constructions, it is generalized to all articles. That is, the requirement that the article and nouninitial vowel display feature agreement (both spreading of [cor] to definites and delinking of [cor] from indefinites) outweighs the motivation for central vowels to acquire place (spreading of [cor] to definites).

In conclusion, we have shown in this paper and in previous work (Goad \& White 2009) that Turkish-speaking L2ers have recourse to several different ways of representing the prosodic structure of English articles. In addition to the previously reported L1-based representations in (22b) and (22d), as well as the L2 appropriate representation in (22c), in the present paper we have found that L2ers adopt a PWd-internal representation which is not, in fact, appropriate for articles in either language, although it is certainly a possible representation cross-linguistically. We have proposed that this representation is motivated in order to satisfy other (L1-based) requirements, in particular the requirement that vowels be realized with place. We note, in conclusion, that none of our subjects exclusively adopted a PWd-internal representation. Consistent with other reports in the literature, there appear to be 'competing' grammars here, with speakers employing more than one prosodic representation for English articles. An explanation of this variability must await future research.

23 As is evident from Table 8, this account will not extend to T4 whose definite article is underlyingly [cor]. We do not know what is triggering harmony in T4's grammar, but it may be revealing that her proportion of definite articles with harmony is somewhat lower than that of any of the other subjects. 


\section{References}

Bobaljik, J.D. 1995. Morphosyntax: On the Syntax of Verbal Inflection. PhD dissertation, MIT. Chomsky, N. and Halle, M. 1968. The Sound Pattern of English. New York: Harper \& Row.

Clements, G.N. and Hume, E. 1995. The internal organization of speech sounds. In The Handbook of Phonological Theory, J. Goldsmith (ed), 245-306. Oxford: Blackwell.

Clements, G.N. and Sezer, E. 1982. Vowel and consonant disharmony in Turkish. In The Structure of Phonological Representations, Vol. 2, H. van der Hulst and N. Smith (eds), 213255. Dordrecht: Foris.

Duffield, N. 1999. Adjectival modification and the specifier-adjunct distinction. In Specifiers: Minimalist Approaches, D. Adger, S. Pintzuk, B. Plunkett and G. Tsoulas (eds), 126-145. Oxford: Oxford University Press.

Embick, D. and Noyer, R. 2001. Movement operations after syntax. Linguistic Inquiry 32: 555595.

Erguvanli, E.E. 1984. The Function of Word Order in Turkish Grammar. Berkeley: University of California Press.

Goad, H. 1993. On the Configuration of Height Features. PhD dissertation, University of Southern California.

Goad, H. and White, L. 2004. Ultimate attainment of L2 inflection: Effects of L1 prosodic structure. In EUROSLA Yearbook 4, S. Foster-Cohen, M. Sharwood Smith, A. Sorace and M. Ota (eds), 119-145. Amsterdam: John Benjamins.

Goad, H. and White, L. 2006. Ultimate attainment in interlanguage grammars: A prosodic approach. Second Language Research 22: 243-268.

Goad, H. and White, L. 2009. Prosodic transfer and the representation of determiners in TurkishEnglish interlanguage. In Representational Deficits in SLA: Studies in Honor of Roger Hawkins, N. Snape, Y.-k. I. Leung and M. Sharwood Smith (eds). Amsterdam: John Benjamins.

Goad, H., White, L. and Steele, J. 2003. Missing inflection in L2 acquisition: Defective syntax or L1-constrained prosodic representations? Canadian Journal of Linguistics 48: 243-263.

Hulst, H. van der and Weijer, R. van de 2004. Vowel harmony. In The Handbook of Phonological Theory, J. Goldsmith (ed), 495-534. Oxford: Blackwell.

Inkelas, S. and Orgun, C.O. 1998. Level (non)ordering in recursive morphology: Evidence from Turkish. In Morphology and its Relation to Phonology and Syntax, S. Lapointe, D. Brentari and P. Farrell (eds), 360-392. Stanford: CSLI.

Inkelas, S. and Orgun, C.O. 2003. Turkish stress: A review. Phonology 20: 139-161.

Ionin, T., Ko, H. and Wexler, K. 2004. Article semantics in L2 acquisition: The role of specificity. Language Acquisition 12: 3-69.

Kabak, B. and Vogel, I. 2001. The phonological word and stress assignment in Turkish. Phonology 18: 315-360.

Kaye, J.D., Lowenstamm, J. and Vergnaud, J.-R. 1985. The internal structure of phonological elements: A theory of charm and government. Phonology Yearbook 2: 305-328.

Kornfilt, J. 1997. Turkish. London: Routledge.

Leung, Y.-k. I. 2005. L2 vs. L3 initial state: A comparative study of the acquisition of French DPs by Vietnamese monolinguals and Cantonese-English bilinguals. Bilingualism: Language and Cognition 8: 39-61.

Lyons, C. 1999. Definiteness. Cambridge: Cambridge University Press.

Newell, H. 2005. The phonological phase. In McGill Working Papers in Linguistics 19, R. Mercado and Y. Furukawa (eds), 21-63.

Ochi, M. 1999. Multiple spell-out and PF adjacency. In Proceedings of the 29th North East Linguistic Society, P. Tamanji (ed), 293-306. Amherst, Mass: GLSA.

Oostendorp, M. van 1998. Schwa in phonological theory. GLOT International 3: 3-8.

Özçelik, Ö. 2008. Footers. Ms., McGill University.

Öztürk, B. 2005. Case, referentiality and phrase structure. Amsterdam: John Benjamins.

Schane, S. 1984. The fundamentals of particle phonology. Phonology Yearbook 1: 129-155. 
Selkirk, E.O. 1996. The prosodic structure of function words. In Signal to Syntax: Bootstrapping from Speech to Grammar in Early Acquisition, J.L. Morgan and K. Demuth (eds), 187-213. Mahwah, NJ: Lawrence Erlbaum.

Sezer, E. 1981. On non-final stress in Turkish. Journal of Turkish Studies 5: 61-69.

Skinner, T. in preparation. Investigations of Downward Movement. PhD dissertation, McGill University.

Snape, N. 2008. Resetting the nominal mapping parameter in L2 English: Definite article use and the count-mass distinction. Bilingualism: Language and Cognition 11: 63-79.

Tsimpli, I.M. 2003. Clitics and determiners in L2 Greek. In Proceedings of the 6th Generative Approaches to Second Language Acquisition Conference (GASLA 2002): L2 Links, J.M. Liceras, H. Zobl and H. Goodluck (eds), 331-339. Somerville, MA: Cascadilla Press.

Underhill, R. (1976). Turkish Grammar. Cambridge, MA: MIT Press. 